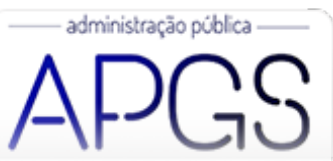

Administração Pública e Gestão Social ISSN: 2175-5787

apgs@ufv.br

Universidade Federal de Viçosa

Brasil

\title{
"FARINHA POUCA, MEU PIRÃO PRIMEIRO": Repartição tributária e o risco moral no federalismo fiscal brasileiro
}

de Almeida Lima, Lauro Vinício; Rêgo de Araújo, Ronaldo José; Lopes Lucena, Wenner Glaucio "FARINHA POUCA, MEU PIRÃO PRIMEIRO": Repartição tributária e o risco moral no federalismo fiscal brasileiro

Administração Pública e Gestão Social, vol. 12, núm. 4, 2020

Universidade Federal de Viçosa, Brasil

Disponible en: http://www.redalyc.org/articulo.oa?id=351564289014

Esta obra está bajo una Licencia Creative Commons Atribución-NoComercial-SinDerivar 3.0 Internacional. 


\title{
“FARINHA POUCA, MEU PIRÃO PRIMEIRO”: Repartição tributária e o risco moral no federalismo fiscal brasileiro
}

\author{
"FARINHA POUCA, MEU PIRÃO PRIMEIRO": Tax distribution and the moral risk in brazilian federal \\ federalism \\ "FARINHA POUCA, MEU PIRÃO PRIMEIRO": Repartimiento tributario y el riesgo moral en el federalismo \\ fiscal brasileño
}

Lauro Vinício de Almeida Lima

Universidade Federal da Paraiba, Brasil

lvinicio2@gmail.com

Ronaldo José Rêgo de Araújo

Universidade Federal de Campina Grande, Brasil

ronaldocontabilidade@ymail.com

Wenner Glaucio Lopes Lucena

Universidade Federal da Paraíba, Brasil

wdlucena@yahoo.com.br

\section{Resumo:}

O objetivo deste caso de ensino é possibilitar discussões sobre os motivos e consequências na repartição tributária que decorrem da adesão ao Convênio ICMS n ${ }^{\circ}$ 73/04 por parte de alguns estados brasileiros, com objetivo de obter isenção do Imposto sobre Mercadorias e Serviços (ICMS) nas operações ou prestações destinadas a órgãos do Poder Executivo da administração púbica estadual direta e suas fundações e autarquias, relacionando-o com as Teorias da Agência e da Escolha Pública e atrelados ao Federalismo Fiscal adotado no Brasil, principalmente no que se refere ao risco moral. Prioritariamente, a aplicação deste caso destina-se aos cursos de graduação e pós-graduação em Administração, Ciências Contábeis, Direito e Economia, por envolver situações comuns correlatas a essas áreas do conhecimento. Os dados foram levantados por meio de análise de documentos e relatórios contábeis disponibilizados nos portais da transparência pública, sendo tratados por meio da análise de conteúdo. Dessa forma, ao explorar os conflitos de agência decorrentes do federalismo fiscal e dos mecanismos incentivadores da alocação dos recursos públicos, a resolução deste caso possibilita aos discentes uma ampliação dos conhecimentos e habilidades de análise sobre a relação entre as teorias estudadas e as realidades praticadas na gestão pública, auxiliando-os em uma reflexão sobre a gestão governamental no que diz respeito à geração de recursos públicos, bem como o reflexo da carga tributária estadual sobre os contratados pela gestão e o seu impacto nas finanças públicas dos governos municipais.

PalaVRas-Chave: Federalismo fiscal, Teoria da agência, Repartição tributária, Convênio ICMS.

\section{AвSTRACT:}

This case of education deals with the economic crisis of collection of federative entities and the problems arising from subterfuges for the reduction of transfers between federative entities, especially the developments resulting from ICMS Agreement $n^{\circ} 73 / 04$, established by the Brazilian states, for concession of exemption from the Tax on Goods and Services (ICMS) in the operations or benefits destined to the organs of the Executive Power of the direct state public administration and its foundations and autarchies. The application of this case is intended for undergraduate and postgraduate courses in Administration, Accounting, Law and Economics, as it involves situations related to these areas of knowledge. Its purpose is to shed light on the reasons and consequences of the tax breakdown resulting from the use of said agreement by some Brazilian states, relating it to the Theories of the Agency and Public Choice and Fiscal Federalism, especially with regard to risk moral and incentives for the agent, represented here by the states, to maximize their benefits over the principal (municipalities). The present work is based on current national and state legislation. The data were collected through analysis of documents and accounting reports made available through the transparency portal, and they were treated through content analysis. Thus, by exploring the conflicts of agencies resulting from fiscal federalism and 
the incentive mechanisms of the allocation of public resources, the resolution of this case of education enables students to expand their knowledge and analytical skills on the relationship between theories and realities practices in public management, helping them to reflect on government tax collection practices, as well as reflecting the state tax burden on those hired by government management and their impact on public finances of municipal governments.

KEYWORDS: Fiscal Federalism, Theory of the agency, Tax distribution, ICMS Agreement.

\section{Resumen:}

Este caso de enseñanza trata de la crisis económica de recaudación de los entes federativos y la problemática derivada de subterfugios para la disminución de los traspasos entre los entes federativos, en especial los desdoblamientos derivados del Convenio ICMS $\mathrm{n}^{\circ}$ 73/04, establecido por los Estados brasileños, para concesión de exención del Impuesto sobre Mercancías y Servicios (ICMS) en las operaciones o prestaciones destinadas a los órganos del Poder Ejecutivo de la administración púbica estatal directa y sus fundaciones y autarquías. Prioritariamente, la aplicación de este caso se destina a los cursos de graduación y posgrado en Administración, Ciencias Contables, Derecho y Economía, por involucrar situaciones relacionadas con esas áreas del conocimiento. El objetivo es arrojar luz sobre los motivos y las consecuencias en el reparto tributario derivado del uso de dicho convenio por algunos Estados brasileños, relacionándola con las Teorías de la Agencia y de la Elección Pública y con el Federalismo Fiscal, principalmente en lo que se refiere al riesgo moral y los incentivos para el agente, aquí representado por los Estados, maximizar sus beneficios en detrimento del principal (Municipios). El presente trabajo se basa en la legislación nacional y estatal vigente. Los datos fueron levantados por medio de análisis de documentos e informes contables disponibilizados en el portal de la transparencia, siendo tratados por medio del análisis de contenido. De esta forma, al explorar los conflictos de agencia derivados del federalismo fiscal y de los mecanismos incentivadores de la asignación de los recursos públicos, la resolución de ese caso de enseñanza posibilita a los alumnos, una ampliación de los conocimientos y habilidades de análisis sobre la relación entre las teorías y las realidades que se practican en la gestión pública, ayudándoles en una reflexión sobre las prácticas de gestión recaudatoria gubernamental, así como el reflejo de la carga tributaria estatal sobre los contratados por la gestión gubernamental y su impacto en las finanzas públicas de los gobiernos municipales.

Palabras Clave: Federalismo fiscal, Teoría de la agencia, Reparto tributario, Convenio ICMS.

\section{INTRODUÇÃO}

O presente caso de ensino trata sobre o uso do Convênio ICMS n 73/04, que é, atualmente, o convênio adotado pelos estados do Acre, Alagoas, Goiás, Mato Grosso, Paraíba, Pernambuco e Piauí. O objetivo do convênio é obter isenção do Imposto sobre Mercadorias e Serviços (ICMS) nas operações ou prestações destinadas a órgãos do Poder Executivo da administração púbica estadual direta e suas fundações e autarquias.

Acerca do desenvolvimento do caso de ensino, este se destina, prioritariamente, aos cursos de graduação e pós-graduação em Administração, Ciências Contábeis, Direito e Economia, porque busca relatar os motivos e consequências na repartição tributária decorrentes do uso do referido convênio pelos estados brasileiros, relacionando-o com a Teoria da Agência, Teoria da Escolha Pública e o Federalismo Fiscal, principalmente no que se refere ao risco moral e aos incentivos para o agente público maximizar os seus benefícios em detrimento dos eleitores.

O risco moral decorreria da possibilidade de os agentes políticos dos estados, como agentes econômicos arrecadadores do ICMS, que posteriormente será compartilhado com os municípios, comportarem-se diferente do esperado no contexto desenhado pelo federalismo fiscal brasileiro (otimização e maximização da arrecadação e recolhimento de recursos para os diversos entes federados). Ao invés de buscar aumentar a arrecadação tributária do ICMS para este ser repartido com os municípios, o estado utilizaria subterfúgios legais para maximizar a sua utilidade na arrecadação, abdicando uma parcela da receita como contrapartida de uma diminuição de despesa em detrimento do interesse dos municípios. Essa "manobra" seria em prol de benefício político individual do gestor do Estado, fazendo com que haja sobra de recursos para aplicálos conforme os seus interesses políticos, o que causaria o problema de agência em questão, que passa a ser detalhado na seção subsequente. 


\section{O Pacto Fiscal Brasileiro: alterações e desdobramentos}

A implementação de qualquer política pública requer recursos financeiros, que são provenientes dos tributos e outras fontes relacionadas ao patrimônio público. Esses recursos são chamados de receitas públicas e sua finalidade consiste em custear as despesas e os investimentos públicos, estabelecidos pelos planos políticos de governo em uma legislação especial chamada de orçamento público.

No tocante à obtenção de recursos em volumes suficientes para fazer frente ao nível de gasto planejado, o gestor público se submete a um desgaste político junto a sua base eleitoral e seus correligionários ao empreender esforços para aumentar e manter a arrecadação dos tributos que estão sob seu controle, sobretudo os impostos. Geralmente, esses impostos são repartidos com outros entes públicos, em razão do federalismo fiscal no qual são compartilhados receitas e despesas, recursos e competências.

No que se refere aos recursos arrecadados, ao serem compartilhados com outros entes federativos ficarão à disposição destes. Dessa forma, seus agentes políticos que não passaram por qualquer atrito com os seus eleitores para sua obtenção poderão cumprir, eventualmente, outras agendas políticas, diferentes das do gestor que se esforçou originalmente na arrecadação dos impostos junto ao seu eleitorado e contribuinte, desgastando a imagem do agente arrecadador. Esta situação pode levar os políticos, que detêm o poder de arrecadar, a utilizarem subterfúgios para não repartir o produto do seu esforço com a arrecadação tributária.

No caso brasileiro, o pacto fiscal estabelecido pela Constituição Federal de 1988, ao reconhecer as dificuldades de arrecadação entre os entes federativos, normatizou que os entes com maiores e melhores potencialidades arrecadatórias repartissem as receitas tributárias com os demais. Com isso, alguns entes passam a ser "meros arrecadadores" de tributos pertencentes a outros entes. Além disso, a Constituição Federal, agora reconhecendo as desigualdades arrecadatórios, conforme legisla o artigo 159 (Constituição Federal, 1988), determinou que os entes que possuem maiores potencialidades econômicas e, portanto, possuidores de maiores volumes de recursos, transferissem uma parcela desses recursos para os entes desfavorecidos economicamente, desenhando a repartição tributária dentro do federalismo brasileiro.

Com esse cenário, em qualquer uma dessas hipóteses, as renúncias de receitas dos impostos, permitidas no ordenamento jurídico brasileiro, sejam elas da União ou dos estados, por intermédio de incentivos fiscais, tornam-se um tema preocupante para as finanças públicas dos entes receptores da repartição tributária, principalmente, os municipais. Isso porque a renúncia de receitas de impostos pode acarretar, por consequência, a queda das receitas dos estados e municípios, desequilibrando as suas contas públicas e inviabilizando a continuidade de prestação de serviços públicos.

Sob esta perspectiva, no Brasil, há um provérbio popular muito antigo relacionado ao individualismo humano: "Farinha pouca, meu pirão primeiro". Essa expressão carrega um sistema simbólico-ideológico forte, que expõe o comportamento egoísta diante de dilemas morais, no qual os interesses individuais se sobrepóem às necessidades coletivas (Castro, 2010). Não é novidade que o ser humano tem um senso de autopreservação, tomando decisões que garantam primariamente a sua sobrevivência quando se depara com situações nas quais a primeira opção poderá trazer consequências danosas não só para sua integridade física, moral e profissional, mas também política. Assim, as decisões políticas, muitas vezes, saltam da esfera altruística, que busca atender o interesse público em geral, para serem determinadas pela satisfação do interesse particular do burocrata.

A título de ilustração, a União, ao conceder isenção de impostos como forma de estímulo ao consumo e geração de emprego e renda, por meio de benefícios fiscais implementados pelo Governo Federal entre os anos de 2011 e 2014, por exemplo, provocou uma queda nos repasses dos impostos federais para os Fundos de Participação dos Estados (FPE) e dos Municípios (FPM), gerando uma crise fiscal séria nos estados e municípios, que atingiu seu ápice em 2015. Como consequência, levando em consideração que o FPE é de $21,5 \%$ e o FPM é de $22,5 \%$ do produto da arrecadação de parte de impostos federais, o impacto daquelas renúncias de receita no FPM no ano de 2015 pode ser vislumbrado no quadro 1. 
Quadro 1 - Impacto da Renúncia fiscal no FPM, pelas desonerações tributárias da União

\begin{tabular}{|c|c|c|c|}
\hline \multicolumn{4}{|l|}{ Montante em ( $\mathrm{R} \$$ bilhões) } \\
\hline Medidas & 2012 & 2013 & 2014 \\
\hline Desoneração da folha de pagamento & 3,8 & 16,0 & 24,7 \\
\hline Desoneração da cesta básica & - & 5,5 & 8,2 \\
\hline Redução do Imposto sobre Produtos & 8,5 & 11,8 & 7,1 \\
\hline $\begin{array}{l}\text { Industrializados (IPI) (automóveis, } \\
\text { caminhŏes, material de construçấo, } \\
\text { linha branca, móveis, papel de parede e } \\
\text { outros) }\end{array}$ & & & \\
\hline $\begin{array}{l}\text { Novas faixas de tributação do Simples e } \\
\text { Microempresa }\end{array}$ & 5,7 & 5,9 & 6,5 \\
\hline $\begin{array}{l}\text { Reintegra - Regime Especial de } \\
\text { Reintegração de Valores Tributários } \\
\text { para as Empresa Exportadoras }\end{array}$ & 3,4 & 3,4 & 2,7 \\
\hline Redução do Imposto sobre Operações & 2,8 & 3,6 & 3,6 \\
\hline $\begin{array}{l}\text { Financeiras (IOF) sobre operações de } \\
\text { crédito para pessoa física (de } 3 \% \text { para } \\
1,5 \%\end{array}$ & & & \\
\hline Banda larga - redes & 0,5 & 1,0 & 1,0 \\
\hline Aumento do limite do lucro presumido & - & - & 1,0 \\
\hline $\begin{array}{l}\text { Alíquota zero do Programa de } \\
\text { Integração Social - Contribuição para o }\end{array}$ & 1,1 & 0,6 & - \\
\hline $\begin{array}{l}\text { Financiamento da Seguridade Social } \\
\text { (PIS /Confins) sobre trigo e massas }\end{array}$ & & & \\
\hline $\begin{array}{l}\text { Redução para zero do prazo de } \\
\text { apropriação dos créditos de PIS /Cofins } \\
\text { sobre aquisição de bens de capital }\end{array}$ & 7,6 & & \\
\hline Demais & 2,2 & 10,9 & 22,0 \\
\hline Total & 44,5 & 70,1 & 88,2 \\
\hline
\end{tabular}

Fonte: Ministério da Fazenda (2015).

Diante desse quadro, pode-se ter uma ideia de que os municípios brasileiros de menor porte são os que mais sofrem com a redução dos repasses para o FPM, em comparação com os estados. A maior dependência dos munícipios em relação ao FPM decorre, muitas vezes, do baixo aparato técnico daqueles entes para majorar e cobrar a arrecadação própria.

Não obstante, os estados, em razão da crise fiscal de 2015, buscaram ampliar sua arrecadação própria, majorando a alíquota do Imposto sobre Circulação de Mercadorias e Serviços (ICMS) e o Imposto sobre Propriedade de Veículos Automotores (IPVA). Em 2015, dezesseis dos vinte e seis estados brasileiros, mais o Distrito Federal, utilizaram desse expediente para ampliar a arrecadação própria em 2016 (Laporta, 2016).

Por via mediata, esperava-se que os municípios se beneficiassem do aumento da alíquota dos impostos estaduais, elevando os repasses para o Fundo de Participação dos Munícipios (FPM), haja vista que pertencem aos mesmos uma parcela da arrecadação do IPVA e do ICMS.

\section{DEPOIS DA QUEDA, O “COICE”}

Atrelado ao problema da queda dos repasses dos impostos federais para o FPM e FPE, no final de 2015, diante do prenúncio de uma recessão econômica no Brasil, a arrecadação tributária nos entes federativos retraiu, gerando uma profunda crise fiscal que provocou atrasos no pagamento de fornecedores e funcionários em alguns estados brasileiros. Assim, o verdadeiro caos instalou-se nos estados e, por ricochete, nos municípios.

O ICMS, imposto de competência dos estados, sua instituição e cobrança, nos termos do inciso II do artigo 155 da Constituição Federal de 1988 (CF/88), é um tributo significante na formação do FPM, uma vez que pertence aos municípios $25 \%$ do produto de sua arrecadação, consoante o inciso IV e o parágrafo único do 
artigo 159 da CF/88. Assim, os estados assumem o papel de "agentes", por possuírem a competência para gerir tributariamente o ICMS, instituindo, cobrando e fiscalizando, e os municípios são os "proprietários" de uma parcela do produto decorrente dessa arrecadação.

A concessão ou revogação de isenções, incentivos e benefícios fiscais do ICMS pelos estados compete ao Conselho Nacional de Política Fazendária (CONFAZ), que promove a celebração de convênios entre os estados, para que possuam validade nacional, de acordo com o previsto no $\$ 2^{\circ}$, inciso XII, alínea "g", do artigo 155 da CF/88 e com a Lei Complementar n. 24, de 7 de janeiro de 1975.

Nesse sentido, em 24 de setembro de 2004, o CONFAZ celebrou o Convênio do ICMS n 73/04, autorizando os Estados do Acre, Alagoas, Mato Grosso, Mato Grosso do Sul, Pernambuco e Piauí a concederem isenção de ICMS nas operações ou prestações destinadas a órgãos do Poder Executivo da administração pública estadual direta e suas fundações e autarquias. Em consequência disso, restou facultado aos estados a concessão de isenção do ICMS incidente nas operações de consumo de bens e serviços licitados, mediante o abatimento do valor correspondente ao valor do ICMS renunciado no preço pago (desconto condicional). Com as alteraçóes posteriores, provavelmente com vistas à crise fiscal que prenunciava, aderiram ao convênio os estados de Goiás (Convênio ICMS n 89/11) e Paraíba (Convênio ICMS n 93/14). Entretanto, saiu do convênio o estado do Mato Grosso do Sul (Convênio ICMS nº 89/11).

Os principais incentivos para os estados concederem a isenção nos termos do Convênio ICMS n ${ }^{\circ} 73 / 04$ que podem ser observados são:

(i) realizar despesas com o preço menor do que foi orçado, sobrando recursos em níveis financeiros e orçamentários para realizar despesas outras;

(ii) redução do risco do contribuinte em não recolher, posteriormente, o ICMS incidente na operação, haja vista que a isenção, mediante desconto proporcional ao preço pago, constitui uma antecipação do ICMS a ser recolhido; e, por fim,

(iii) Aumentar seus recursos próprios ao não realizar a partilha tributária do ICMS decorrente das operações de consumo do estado, haja vista que não haverá qualquer arrecadação de ICMS a ser partilhada.

A Lei de Responsabilidade Fiscal (LRF), Lei Complementar 101/2000, no seu art. 14, determina que a concessão ou ampliação de incentivo ou benefício de natureza tributária da qual decorra renúncia de receita deverá estar acompanhada de estimativa do impacto orçamentário-financeiro no exercício em que deva iniciar sua vigência e nos dois seguintes, atendendo ao disposto na lei de diretrizes orçamentárias e, pelo menos, uma das seguintes condições: Apresentação da demonstração de que a renúncia foi considerada na estimativa de receita da lei orçamentária e de que não afetará as metas de resultados fiscais previstas no anexo próprio da lei de diretrizes orçamentárias e adoção de medidas compensatórias, por meio do aumento de receita, decorrentes de elevação de alíquotas, ampliação da base de cálculo, majoração ou criação de tributo ou contribuição.

São consideradas renúncias de receitas aquelas decorrentes de anistia, remissão, subsídio, crédito presumido, concessão de isenção em caráter não geral, alteração de alíquota ou modificação de base de cálculo que implique redução discriminada de tributos ou contribuições e outros benefícios que correspondam a tratamento diferenciado e que podem ser legisladas por meio de decreto (Lei Complementar n. 101, 2000).

O decreto é um ato emanado pelo chefe do Poder Executivo ou gestor do governo. Como tal, esse ato sofre controle dos demais Poderes da República do Brasil: Legislativo e Judiciário. Ao Poder Legislativo compete, além de legislar, fiscalizar, com auxílio do Tribunal de Contas, os atos do Poder Executivo, exercendo o controle político-administrativo e o financeiro-orçamentário. Quanto ao Poder Judiciário, cabe a aplicação da lei no caso concreto, apresentando resultado a um conflito no caso concreto (Novelino, 2015).

A título de esclarecimento, em boa parte dos estados brasileiros, o chefe do Poder Executivo detém parcerias com a maioria dos representantes da Assembleia Legislativa e, no tocante aos decretos exarados pelos governadores para adesão ao Convênio do ICMS n $n^{\circ} 73 / 04$, não há relatos de qualquer ação para o controle político-administrativo e financeiro-orçamentário contra o mesmo. Também não foram 
encontradas quaisquer medidas que denotem irresignação por parte dos municípios (prefeitos, câmaras de vereadores e cidadãos) provocando o Judiciário para que fizesse o controle concreto da legislação atinente ao Convênio do ICMS n ${ }^{\circ} 73 / 04$, ou sua adesão, em sentido abstrato, o que demonstra a perfeita admissibilidade da situação aqui apresentada em quaisquer estados e municípios do Brasil.

\section{O Dilema: "Farinha Pouca, Meu Pirão Primeiro"}

A alíquota geral do ICMS nos estados, em média, é de $18 \%$, integrando o preço de todas as mercadorias e serviços de transporte e telecomunicação que circulam dentro do território do estado, consoante o art. $2^{\circ}$ da Lei Complementar 87/1996. Com a concessão de sua isenção, nos termos do Convênio do ICMS n 73/04, os estados obtêm:

(i) incremento de $18 \%$ no total dos gastos orçamentários previstos com aquisição de mercadorias e serviços sobre os quais incida o ICMS, pois a isenção diminui o valor pago pelo preço licitado, sobrando mais recursos para serem direcionados a outros gastos da mesma natureza;

(ii) antecipação do recebimento do ICMS incidente nas aquisições das mercadorias e serviços por ela consumidos, porque o desconto representa retenção de dinheiro no caixa, ocasionando maior disponibilidade de recursos para o governo;

(iii) adjudicação dos 25\%, dos 18\% do ICMS, que deveriam ser repassados aos municípios caso houvesse a efetiva arrecadação daquele imposto.

Apesar disso, os estados não divulgam informação sobre os termos do pagamento realizado ao licitante, publicando se concedeu, ou não, o benefício fiscal, com o correspondente abatimento no preço, o que acaba por ser um fator limitante neste caso, recorrendo, portanto, a estimativas desses valores.

A título de exemplificação, no estado da Paraíba (dados obtidos do Sagres, 2018), na execução orçamentária de 2017, foram registradas em Outras Despesas Correntes (aquisição de materiais, serviços e outros que podem incidir ICMS) na ordem de $\mathrm{R} \$ 2.829 .313 .106,11 \mathrm{e}$, como Despesas de Investimento (que também podem incidir ICMS), o valor de R \$563.581.792,29, consoante informações obtidas na Secretaria do Tesouro Nacional (STN). Com isso, há um potencial base de cálculo do ICMS no montante de R \$3.392.894.898,40 sobre as operações que envolvem o consumo de bens e serviços do estado da Paraíba. O ICMS provável incidente sobre aquela base de cálculo, levando em consideração a alíquota geral aplicada pela Paraíba (18\%), representaria um aumento na arrecadação do ICMS no valor de $\mathrm{R} \$ 610.721 .081,71$, do qual uma parcela de $25 \%$ deveria ser destinada para o FPM, no valor de R\$152.680.270,43. O total do ICMS arrecadado pelo estado da Paraíba em 2017 foi de R\$5.066.473.000,00. Deste valor, R\$1.266.618.250,00 foram destinados ao FPM. Neste cenário, a utilização do Convênio ICMS n $73 / 04$ representa uma redução provável no total do repasse do ICMS pelo estado aos municípios de 12,05\%.

Tabela 1 - Demonstrativo do Potencial de Arrecadação de ICMS que o Convênio do ICMS n. 73/04 reflete no Orçamento Anual do Governo do Estado da Paraíba no Exercício 2017

\begin{tabular}{|c|c|c|c|c|}
\hline $\begin{array}{l}\text { Despesa } \\
\text { Liquidada (a) }\end{array}$ & $\begin{array}{l}\text { Potencial de } \\
\text { Arrecadação de } \\
\text { ICMS (b) = } a^{*} \\
18 \%\end{array}$ & $\begin{array}{l}\text { Potencial de } \\
\text { destinação para } \\
\text { o FPM (c) = } \\
\text { (b) } * 25 \%\end{array}$ & $\begin{array}{l}\text { Arrecadação } \\
\text { Realizada de } \\
\text { ICMS em } 2017 \\
\text { (d) }\end{array}$ & $\begin{array}{l}\text { Percentual } \\
\text { do } \\
\text { Potencial } \\
\text { de ICMS } \\
\text { (e) }= \\
{[(\text { b) } /(\text { d) }} \\
]^{* 100}\end{array}$ \\
\hline $3.392 .894 .898,40$ & $610.721 .081,71$ & $152.680 .270,43$ & $5.066 .473 .000,00$ & $12,05 \%$ \\
\hline
\end{tabular}


Ainda neste contexto, o estado da Paraíba possui 223 municípios, dentre os quais a maioria tem uma forte dependência financeira em relação ao Fundo de Participação Municipal na arrecadação dos tributos federais e estaduais (FPM) para arcar com o orçamento geral do município. Ademais, o poder público estadual da Paraíba, em se tratando de investimentos e prestação de serviços, é o maior consumidor de bens e serviços nos municípios, característica que permeia boa parte do território nacional. Já que é um Estado relativamente pobre em comparação aos demais do Brasil, o governo estadual é o maior consumidor individual de bens e serviços no âmbito do seu território, em razão da oferta de serviços públicos e realizações de investimentos, ganhando maior relevância para o FPM a diminuição de repasse do ICMS pelo estado da Paraíba.

Neste panorama, é notória a relação de agência estabelecida na cobrança do ICMS pelo estado da Paraíba e posterior entrega de parte de sua arrecadação para os seus municípios. Com a concessão da isenção, há a concretização do risco moral de o estado comportar-se de forma adversa ao que se esperava, quando encontrou incentivos para atuar de forma a maximizar seus benefícios, em detrimento dos municípios, que são expropriados de sua parcela de participação de $25 \%$ do total do desconto percentual aproveitado pelo Estado paraibano.

De forma ilustrativa, buscou-se demonstrar uma estimativa do potencial de arrecadação do ICMS em cada um dos estados brasileiros, sob a hipótese de que cada um dos entes federativos endossem o Convênio do ICMS n. 73/04. Os resultados encontram-se na Tabela 2. 
Tabela 2 - Estimativa do Potencial de Arrecadação de ICMS que o Convênio do ICMS n. 73/04 reflete nos Orçamentos Anuais dos Governos Estaduais Brasileiros no Exercício 2017

\begin{tabular}{|c|c|c|c|c|c|}
\hline $\begin{array}{l}\text { Governo do } \\
\text { Estado }\end{array}$ & $\begin{array}{l}\text { Despesa Liquidada } \\
\text { (a) }\end{array}$ & $\begin{array}{l}\text { Potencial de } \\
\text { Arrecadação de } \\
\text { ICMS }(b)=a * 18 \%\end{array}$ & $\begin{array}{l}\text { Potencial de } \\
\text { destinação para o } \\
\text { FPM (c) = (b)*25\% }\end{array}$ & $\begin{array}{l}\text { Arrecadação } \\
\text { Realizada de ICMS } \\
\text { em } 2017 \text { (d) }\end{array}$ & $\begin{array}{l}\text { Percentual } \\
\text { do } \\
\text { Potencial } \\
\text { de ICMS } \\
\text { (e) }= \\
\text { [(b) } /(\text { d) } \\
]^{\star 100}\end{array}$ \\
\hline Acre & $1.738 .255 .074,43$ & $312.885 .913,40$ & $78.221 .478,35$ & $1.115 .901 .671,40$ & $28,04 \%$ \\
\hline Alagoas & $3.552 .009 .870,74$ & $639.361 .776,73$ & $159.840 .444,18$ & $3.852 .121 .016,40$ & $16,60 \%$ \\
\hline Amapá & $1.237 .929 .099,77$ & $222.827 .237,96$ & $55.706 .809,49$ & $3.676 .880 .000,00$ & $6,06 \%$ \\
\hline Amazonas & $6.815 .009 .700,66$ & $1.226 .701 .746,12$ & $306.675 .436,53$ & $8.085 .783 .373,97$ & $15,17 \%$ \\
\hline Bahia & $20.930 .569 .634,84$ & $3.767 .502 .534,27$ & $941.875 .633,57$ & $17.751 .046 .000,00$ & $21,22 \%$ \\
\hline $\begin{array}{l}\text { Ceará } \\
\text { Espirito }\end{array}$ & $11.299 .124 .770,59$ & $2.033 .842 .458,71$ & $508.460 .614,68$ & $11.181 .546 .915,96$ & $18,19 \%$ \\
\hline Santo & $4.092 .091 .216,37$ & $736.576 .418,95$ & $184.144 .104,74$ & $9.044 .470 .581,26$ & $8,14 \%$ \\
\hline Goiás & $7.022 .481 .421,70$ & $1.264 .046 .655,91$ & $316.011 .663,98$ & $19.174 .389 .209,17$ & $6,59 \%$ \\
\hline Maranhão & $7.429 .045 .115,82$ & $1.337 .228 .120,85$ & $334.307 .030,21$ & $6.366 .503 .360,38$ & $21,00 \%$ \\
\hline $\begin{array}{l}\text { Mato Grosso } \\
\text { Mato G. do }\end{array}$ & $4.332 .140 .383,98$ & $779.785 .269,12$ & $194.946 .317,28$ & $10.986 .044 .311,05$ & $7,10 \%$ \\
\hline $\begin{array}{l}\text { Sul } \\
\text { Minas }\end{array}$ & $3.681 .532 .577,52$ & $662.675 .863,95$ & $165.668 .965,99$ & $7.611 .209 .606,34$ & $8,71 \%$ \\
\hline Gerais & $25.589 .604 .874,53$ & $4.606 .128 .877,42$ & $1.151 .532 .219,35$ & $38.493 .390 .834,40$ & $11,97 \%$ \\
\hline Pará & $9.409 .643 .000,00$ & $1.693 .735 .740,00$ & $423.433 .935,00$ & $10.115 .628 .000,00$ & $16,74 \%$ \\
\hline Paraíba & $3.392 .894 .898,40$ & $610.721 .081,71$ & $152.680 .270,43$ & $5.066 .473 .000,00$ & $12,05 \%$ \\
\hline Paraná & $24.085 .455 .913,74$ & $4.335 .382 .064,47$ & $1.083 .845 .516,12$ & $29.512 .203 .716,20$ & $14,69 \%$ \\
\hline Pernambuco & $13.268 .680 .624,51$ & $2.388 .362 .512,41$ & $597.090 .628,10$ & $14.152 .878 .900,00$ & $16,88 \%$ \\
\hline $\begin{array}{l}\text { Piauí } \\
\text { Rio de }\end{array}$ & $3.168 .893 .404,10$ & $570.400 .812,74$ & $142.600 .203,18$ & $3.780 .359 .865,30$ & $15,09 \%$ \\
\hline $\begin{array}{l}\text { Janeiro } \\
\text { Rio G. do }\end{array}$ & $23.912 .505 .091,70$ & $4.304 .250 .916,51$ & $1.076 .062 .729,13$ & $32.570 .081 .000,00$ & $13,21 \%$ \\
\hline $\begin{array}{l}\text { Norte } \\
\text { Rio G. do }\end{array}$ & $2.167 .525 .467,51$ & $390.154 .584,15$ & $97.538 .646,04$ & $5.065 .705 .917,66$ & $7,70 \%$ \\
\hline Sul & $20.003 .977 .942,90$ & $3.600 .716 .029,72$ & $900.179 .007,43$ & $31.213 .973 .645,76$ & $11,54 \%$ \\
\hline Rondônia & $2.270 .773 .440,99$ & $408.739 .219,38$ & $102.184 .804,84$ & $3.283 .719 .481,74$ & $12,45 \%$ \\
\hline $\begin{array}{l}\text { Roraima } \\
\text { Santa }\end{array}$ & $1.585 .667 .701,02$ & $285.420 .186,18$ & $71.355 .046,55$ & $778.295 .037,00$ & $36,67 \%$ \\
\hline Catarina & $7.965 .089 .190,81$ & $1.433 .716 .054,35$ & $358.429 .013,59$ & $19.067 .055 .218,75$ & $7,52 \%$ \\
\hline São Paulo & $98.987 .622 .000,00$ & $17.817 .771 .960,00$ & $4.454 .442 .990,00$ & $126.783 .019 .000,00$ & $14,05 \%$ \\
\hline Sergipe & $7.792 .392 .973,46$ & $1.402 .630 .735,22$ & $350.657 .683,80$ & $3.201 .570 .000,00$ & $43,81 \%$ \\
\hline Tocantins & $8.119 .606 .914,23$ & $1.461 .529 .244,56$ & $365.382 .311,14$ & $2.536 .402 .000,00$ & $57,62 \%$ \\
\hline TOTAL & $323.850 .522 .304,32$ & $58.293 .094 .014,79$ & $14.573 .273 .503,07$ & $424.466 .651 .662,74$ & $13,73 \%$ \\
\hline
\end{tabular}

Fonte: Secretaria do Tesouro Nacional (STN, 2018), Portais da Transparência

(2018) e Secretaria Nacional de Política Fazendária (CONFAZ, 2018).

A Despesa Liquidada corresponde aos valores executados nas rubricas Outras Despesas Correntes e Investimentos;

A Receita Realizada corresponde ao montante de ICMS arrecadado, conforme demonstrado na Receita Corrente

Líquida de cada ente federativo; pressupóe-se a alíquota de 18\% de ICMS para todos os estados da federação.

Notas: A Despesa Liquidada corresponde aos valores executados nas rubricas Outras Despesas Correntes e Investimentos; A Receita Realizada corresponde ao montante de ICMS arrecadado, conforme demonstrado na Receita Corrente Líquida de cada ente federativo; pressupõe-se a alíquota de 18\% de ICMS para todos os estados da federação.

Fonte: Secretaria do Tesouro Nacional (STN, 2018), Portais da Transparência (2018) e Secretaria Nacional de Política Fazendária (CONFAZ, 2018).

De acordo com os dados da Tabela 2, estima-se que, em média, os estados brasileiros deixariam de arrecadar 13,73\% do ICMS anual, caso passassem a adotar o Convênio do ICMS n. 73/04, o que seria 
revertido em folga orçamentária e financeira para o executivo estadual, possibilitando destinar tais recursos para outras áreas de seu interesse. Todavia, os dados apontam que $\mathrm{R} \$ 14,5$ bilhões deixariam de ser repassados para as municipalidades a título de Fundo de Participação dos Municípios, o que sugere uma redução e (ou) complicação da autonomia financeira municipal. Isso porque os estados devem ser agentes meramente arrecadatórios dos recursos constitucionalmente pertencentes aos municípios, como mecanismo de arrecadação posto pelo federalismo brasileiro. Assim, tais resultados demonstram a substancialidade do conflito de agência existente entre o estado e seus municípios, no caso apresentado, reflexo do federalismo adotado no Brasil.

\section{Notas DE Ensino}

\section{Fonte de dados}

Este relato de caso é baseado nas diretrizes da Constituição Federal do Brasil de 1988, em particular os seus artigos $1^{\circ}, 3^{\circ} 18,157,158$ e 159, na Lei Complementar 87/1996 e no Convênio ICMS 73/04 do Conselho Nacional de Política Fazendária (CONFAZ). Os dados foram levantados por meio de análise de documentos e relatórios contábeis disponibilizados no Conselho Nacional de Política Fazendária, na Secretaria do Tesouro Nacional e em portais da transparência dos estados federativos.

\section{Aspectos Pedagógicos}

A sugestão para a aplicação do presente caso de ensino é em uma aula dividida em dois momentos. Considerando que uma explicação mais aprofundada sobre as Teorias da Agência e Teoria do Federalismo já tenha sido previamente feita pelo tutor, a primeira parte da dinâmica da aula seria pedir aos alunos que formassem um círculo na sala para debater e explorar os principais aspectos abordados pelas teorias, relacionando-as com a situação aqui apresentada. $\mathrm{O}$ tutor deve assumir o papel de estimular um pensamento crítico nos alunos.

Após a primeira etapa, o docente explicaria aos alunos o estudo de caso e a sua problematização. $\mathrm{Na}$ etapa seguinte, sugere-se dividir a turma em pequenos grupos, de forma que eles debatam entre si questões específicas direcionadas pelo professor, identificando os principais problemas encontrados no caso relatado e propondo soluções, colocando-os na posição de consultores para a análise desta problemática e expondo, posteriormente, os resultados para o restante da turma. Por fim, o docente deve fazer uma análise crítica das respostas de cada grupo e levantar os pontos positivos, indicando leituras complementares para os alunos.

\section{Questões propostas para discussão}

1. Conforme o arranjo de repartição das receitas do ICMS, quem é o "agente" e o "principal”? Em algum momento há inversão entre os papeis?

2. Quem são os principais prejudicados com a adoção do Convênio ICMS nº 73/04?

3. Em que ponto a teoria da agência se relaciona com os fatos ocorridos?

4. Em que ponto a teoria do federalismo fiscal se relaciona com os fatos ocorridos?

5. Há assimetria da informação e risco moral na relação entre os estados e municípios?

6. Qual a relação entre o caso e a teoria da escolha pública? 
7. Levando em consideração que a alíquota média do ICMS é de $18 \%$ e que irá incidir sobre todas as despesas liquidadas de outros gastos e investimentos pelos estados, qual o percentual médio de impacto na redução do repasse do ICMS para o FPM?

8. Em cada estado que adotou o Convênio ICMS n 73/04, qual seria valor do ICMS incidente sobre as suas despesas liquidadas de outros gastos e investimentos e o quanto este valor representa percentual no FPM?

9. Quais as possíveis soluções para o problema apresentado?

10. Analise novamente os eventos e indique qual (ou quais) outra (outras) teoria (teorias) poderia (poderiam) ser aplicada (aplicadas) ao contexto descrito pelo caso de ensino, na sua percepção.

\section{Exposição Teórica}

\section{Federalismo Fiscal Brasileiro}

Discutir o federalismo fiscal exige a compreensão de descentralização, ou seja, as divisões de tarefas no âmbito da federação. A União, os estados e os municípios possuem obrigações definidas e comuns. Normalmente, os serviços públicos prestados estão ligados à especificidade local, regional ou nacional. Tratando-se de serviços públicos de interesse nacional, estes são obrigações da União; regional, dos estados, e local, dos municípios. Obviamente, existem atividades que são comuns a todos os entes federados, como saúde, educação, segurança, dentre outros que possuem conotações de interesse de todos os níveis, que são mutuamente compartilhadas com todos os entes. Por exemplo, a segurança, que possui guarda municipal, polícias estaduais e polícias federais, ou a saúde, com hospitais federais, estaduais e municipais (Mendes, 2004).

Esta divisão de tarefas ou serviços públicos a serem ofertados decorre do pacto federativo, no qual os entes federados transferem uma parcela do arbítrio para algo maior que una os participantes em torno de um objetivo comum, o estado federado ou o país. Esse pacto federativo é consubstanciado pela Constituição Federal, onde são delineadas as regras sob a égide em que os entes federados estão submetidos, relacionandoas a seus direitos e obrigações (Affonso, 1995).

Não obstante, para a prestação dos serviços públicos faz-se necessária a obtenção de recursos para fazer frente às despesas. Estes, em sua grande maioria, são derivados dos cidadãos, sendo as fontes de recursos distribuídas consoante à divisão de tarefa entre os diferentes níveis de governo. Os maiores níveis de governo, que ofertaram maior quantidade de serviços, devem arrecadar mais e quem arrecada mais normalmente auxilia os que arrecadam menos por intermédio de transferências que podem ser voluntárias ou obrigatórias, esta última decorrente da repartição tributária (Mendes, 2004).

O federalismo fiscal brasileiro e a sua descentralização de atribuições e de receitas dos entes federados estão estabelecidos pelos artigos $1^{\circ}, 3^{\circ} 18,157,158$ e 159 da Constituição Federal do Brasil.

Os tributos são definidos como uma prestação pecuniária compulsória, expressa em valores monetários ou monetariamente mesurável, que não seja proveniente de uma sanção por um ato ilícito, instituída por lei e cobrada por intermédio de uma atividade administrativa plenamente vinculada (Lei Complementar n. 87, 1966).

Com isso, as empresas são obrigadas a recolher aos cofres públicos valores incidentes direta ou indiretamente sobre as suas atividades econômicas sob a denominação de tributos. No Brasil, os tributos compreendem os impostos, taxas, contribuições melhorias, contribuições especiais e empréstimos compulsórios, sendo a sua competência tributária para instituição autorizada, de acordo o art. 145 da Constituição Federal, à União, aos estados, ao Distrito Federal e aos municípios.

Os impostos são uma espécie de tributo cuja arrecadação não possui destinação específica, podendo ser utilizados para arcar com as atividades da estrutura administrativa do governo ou mesmo os serviços públicos em geral. As taxas são tributos vinculados à contraprestação de um serviço prestado ou posto à disposição 
pelo poder público. As contribuições podem ser divididas em duas: As de melhoria, cobradas em decorrência de uma valorização imobiliária de uma obra pública, em que o contribuinte paga o tributo em função do seu enriquecimento ocasionado pela obra, limitando-se ao valor incremental de valorização ou ao valor da obra rateada pelos contribuintes afetados, e as contribuições especiais, cobradas de determinado grupo para uma destinação específica ou para fins sociais. Por fim, os empréstimos compulsórios são empréstimos decorrentes de uma lei complementar, de arrecadação vinculada em função de situação emergencial ou para outro fim específico, restituíveis ao contribuinte no fim de determinado prazo (Godoi \& Mello, 2016).

No art. 159 da CF/88 está estabelecida a repartição das receitas tributárias, onde o ente federado que possui competência para instituição e cobrança do tributo tem como obrigação repartir o produto daquela arrecadação com os entes de menor dimensão, conforme o Quadro 2.
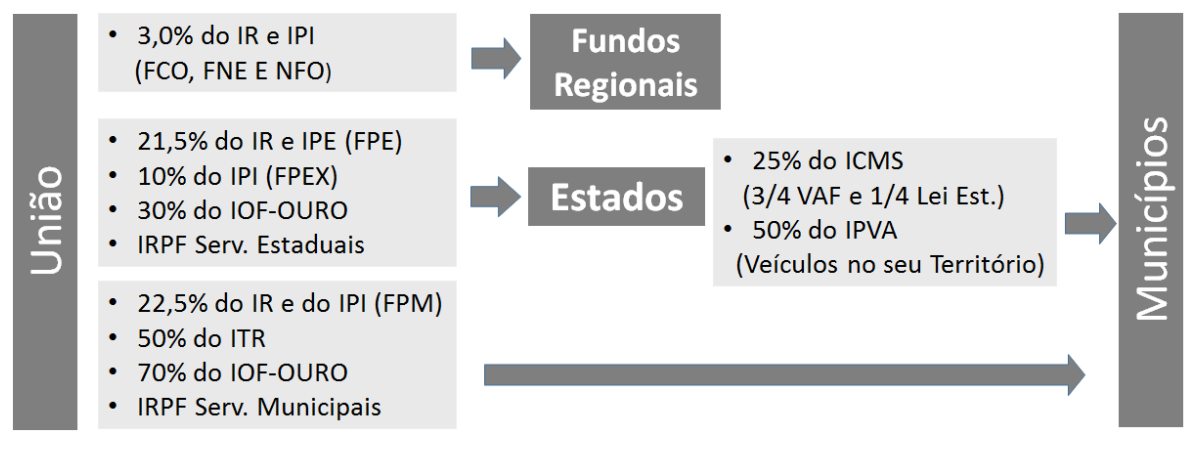

Quadro 2 - Repartição Tributária Brasileira Fonte: Baseado na Constituição Federal de 1988.

Nota: IR = Imposto de Renda; IRPF = Imposto de Renda Pessoa Física; IPI= Imposto sobre Produtos Industrializados; IOF = Imposto sobre Operações Financeiras; ITR = Imposto Territorial Rural; ICMS = Imposto sobre Circulação de Mercadorias e Serviços de Transporte e Telecomunicações; IPVA = Imposto sobre Propriedade de Veículos Automotores; VAF = Valor Adicionado Fiscal. (Elaboração Própria).

Em se tratando do ICMS, nos termos do art. 159 da CF/88, pertencem aos municípios $25 \%$ do produto de sua arrecadação pelo estado, sendo distribuído da seguinte forma:

1. Três quartos da arrecadação decorrente da circulação de mercadorias e serviços no âmbito do território do município, este total é denominado Valor Adicionado Fiscal (VAF);

2. Um quarto conforme dispuser a lei estadual.

Nesse prelo, os municípios mais pobres e que recebem maior quantidade de bens e serviços frutos de licitação dos estados geralmente são os mais dependentes de repasses tributários. Dos $25 \%$ da arrecadação do ICMS decorrente dos bens e serviços disponibilizados pelos estados no território dos municípios, 75\% deveriam ser destinados ao seu orçamento, conforme a Constituição Federal Brasileira. A dependência dos municípios desprovidos economicamente dos repasses do FPM exacerba a importância do produto da arrecadação do ICMS decorrente dos bens e serviços consumidos em decorrência de processo licitatório pelos estados no território dos municípios brasileiros.

\section{Teoria da agência e Risco Moral atrelada a Teoria das Escolhas Públicas}

Jensen e Meckling (2008) explicaram a relação de agência como uma delegação de poderes de decisão dada para o agente, em uma relação contratual na qual uma ou mais pessoas (principal) emprega outra pessoa (o agente) para realizar algum serviço ou trabalho em seu favor. Com isso, se as duas partes procuram maximizar suas utilidades, existirá uma boa razão para crer que o agente não irá atuar de acordo com os interesses do principal. No cenário político, os eleitores delegam a função de gestão ao político, que irá decidir por representação da maioria em benefício da população. 
A teoria da agência analisa as relações entre os participantes de um sistema, onde a propriedade e controle são designados a pessoas diferentes, ocasionando conflitos de interesse entre os indivíduos e resultando custos em função da separação entre a propriedade e o controle de capital. No contexto, também é possível verificar uma relação de agência quando há a participação passiva do governo de menor magnitude, aguardando os resultados da repartição tributária do governo de maior magnitude, por força do federalismo fiscal, compreendido como um vínculo contratual em que o governo que arrecadada será o agente e o governo que recebe o repasse é principal (Mutlu, Peng, \& Van Essen, 2015).

Desse modo, a relação de agência como um modelo de tomada de decisão para mais de um indivíduo, tendo um enfoque prescritivo, embasado num modelo normativo, envolve a teoria da utilidade, na qual um dos indivíduos é o agente (estado), e o outro, o principal (os municípios). O primeiro cumpre certas tarefas para o segundo, que se compromete a investir os recursos recebidos em prol da sociedade (repasse tributário). O principal é o avaliador das informações enquanto o agente assume o papel de tomador de decisão, optando pelas melhores alternativas de decisão das informações que deveriam estar disponíveis ao principal (Kleven, Kreiner, \& Saez, 2016).

Seguidamente, Jensen e Meckling (2008) trataram dos riscos inerentes à relação de agência utilizando o mercado de seguros para explicar que alguns indivíduos têm maior propensão a acidentes ou morte que outros e detendo maior conhecimento sobre seu risco que o segurador (seleção adversa). Sendo o valor do prêmio igual para todos os segurados, esses indivíduos de maior risco poderão adquirir apólices maiores e, por consequência, desequilibrar a estrutura de distribuição de risco da empresa seguradora (risco moral). O mesmo pode ocorrer na relação do federalismo fiscal entre os municípios (segurador) e os estados (segurado).

É perceptível o risco de seleção adversa que os eleitores podem incorrer ao elegerem governadores que priorizem a retenção de recursos ao invés de repassá-los para os municípios, valendo-se da assimetria informacional acerca da arrecadação tributária e dos atos e fatos a ela relacionados, e o risco moral, por sua vez, por parte do gestor público estadual, quando se comporta de forma diversa do esperado no pacto federativo, postergando, diminuindo ou elidindo o repasse de recursos para os municípios.

O risco moral decorre da possibilidade de uma parte, em uma relação contratual, mudar de comportamento ante as situações de contextos diferentes em que ocorra alguma transação econômica. Nessa acepção, o risco moral está associado à assimetria informacional, sendo esta compreendida como a existência de um cenário onde uma parte está guarnecida de maiores informações do que a outra parte envolvida na transação. Sob o baluarte dessa conjuntura, nos vínculos contratuais, onde existam as figuras do agente e principal, é possível que o agente, posteriormente, tenha incentivos ou tendências a agir em interesse próprio, em detrimento do principal, à medida que o agente detém mais informações sobre suas ações que o principal e, em virtude disso, poderia agir inapropriadamente, caso os seus interesses não estejam alinhados ao do principal (Eisenhardt, 2015). A aplicação dos conceitos e métodos econômicos ligados à Teoria da Agência são abarcados pela Teoria da Escolha Pública na análise do comportamento político.

A Teoria da Escolha Pública é uma ramificação das ciências políticas e econômicas que tem o propósito de observar o processo de tomada de decisão nas instituições públicas. Schumpeter (1942) foi um dos pioneiros da teoria quando avaliou o papel do governo na sociedade. Seguidamente, na década de 1950, surgiram trabalhos de aspectos matemáticos defendendo que as escolhas econômicas dos gestores públicos estão correlacionadas com a expectativa de suas reeleições (Arrow, 1951; Downs, 1957). Destacaram-se, também, no estudo James Buchanan e Gordon Tullock na obra "Calculus of consent" (1962) e o estudo "Government failure - a primer in public choice" de Tullock, Brandy e Seldon (2002).

Buchanan e Tullock (1962) trouxeram a concepção da escolha pública como uma "política sem romance", dissociando a imagem dos gestores públicos da visão de que eles irão buscar o bem da coletividade. Assim, incorporam o raciocínio de que o processo de escolha no setor público sofre das mesmas influências relacionadas à iniciativa privada, em razão da natureza humana, pois aqueles que decidem teriam motivos para adotarem escolhas que também beneficiem os seus interesses. 
Tullock, Brandy e Seldon (2002) utilizam ferramentas da economia para demonstrar que os agentes políticos agem igualmente como na vida privada, visando maximizar os seus interesses. Nesse ponto, observando as falhas no sistema, os autores trazem elementos que indicam deficiências no sistema democrático, como a negociação dos votos (logrolling), o lobbying organizado, grupos de pressão, o uso de recursos próprios para obtenção de ganhos pessoais (rent seeking) e a burocracia (as pessoas estão mais interessadas no seu próprio bem-estar) (Cruz, 2011).

Em resumo, a Teoria da Escolha Pública propõe analisar inúmeras perspectivas como o funcionamento dos diferentes mecanismos de voto, explicando que não há um mecanismo ideal para obter escolhas sociais a partir das preferências individuais; as falhas de governo associadas à falha de eficiência económica das decisões económicas e à injustiça na repartição do rendimento; o horizonte temporal curto dos governantes eleitos; a necessidade de existência de uma restrição orçamental para os diferentes grupos de despesas; a eficiência econômica de algumas formas de financiamento dos partidos e das eleições, dentre outros.

Com relação ao federalismo fiscal, verifica-se que a escolha pública exerce uma influência preponderante para o arranjo do sistema financiamento adotado no país. Normalmente, é o pacto constitucional que define o sistema federado e sua forma de organização política, administrativa e financeira. Dessa forma, há um vínculo contratual no qual os gestores públicos estão condicionados e devem cumprir com as suas prescrições. Todavia, em função da impossibilidade de firmar um contrato completo, há lacunas no sistema que permitem que os gestores públicos atuem discricionariamente, ante a liberdade outorgada pelo sistema para que eles decidam diante de opções igualmente válidas perante o sistema legal vigente. Neste momento, abre-se a possibilidade de o governante agir de forma oportuna, conforme vislumbrado na Teoria da Agência ao tratar da seleção adversa e do risco moral.

No tocante à situação proposta neste trabalho, em que os estados utilizam um convênio para conceder benefícios fiscais que se reverterão a seu favor, por intermédio de desconto no preço pago pelos insumos utilizados, percebe-se que há uma diminuição da despesa pública que irá permitir um excedente de caixa com a capacidade de ser utilizado para outras despesas públicas. Com isso, o gestor público expõe para a sociedade um aumento na eficiência dos gastos públicos sob sua gestão ao reduzir os valores das despesas públicas, ao tempo que reduz o valor da parcela dos impostos que deveriam ser repassados para o município, ao elidir a incidência do imposto com o uso da isenção fiscal, em total detrimento às finanças municipais.

Esse comportamento oportunista revela o risco moral no qual o federalismo fiscal está exposto, por intermédio de escolhas públicas adotadas pelos políticos que estão à frente dos governos de maior magnitude, em detrimento dos governos de menor magnitude, em função de políticas públicas fiscais que venham reduzir os repasses do FPE e FPM.

Por todo exposto, verifica-se, nesta proposição, que, para não ficarem em uma situação financeira deficitária, os munícipios devem provocar os instrumentos de controle estabelecidos no ordenamento jurídico, para evitar a ingerência da União e dos estados que tendam a diminuir dos repasses para o FPM. Sobretudo no que diz respeito às parcelas compartilhadas pelos estados, caso os municípios não questionem a adoção do Convênio ICMS n ${ }^{\circ} 73 / 04$, os repasses do ICMS decorrente dos gastos públicos estaduais para FPM se reduziriam à medida que a atuação do estado seja ampliada.

Ainda, no Convênio ICMS $n^{\circ} 73 / 04$, verifica-se a total assimetria informacional entre os agentes envolvidos, que irá ampliar o risco de agência no federalismo fiscal adotado. Observa-se isto quando, na qualidade de "agente", o estado tem a posse de um conjunto maior de informações sobre as peculiaridades e resultados das operações relacionados ao ICMS, se comparados aos municípios, mesmo estes tendo o papel de "principal", por serem os proprietários, de fato, dos $25 \%$ do produto da arrecadação do ICMS no âmbito do seu território (Crespi, Giuliondori, Giuliodori, \& Rodiguez, 2016).

Assim, as discussões que podem surgir desta provocação deverão ajudar o professor nos apontamentos do conflito de agência existente que se reflete, de forma trivial, nas finanças públicas dos municípios e estados 
brasileiros, o que promoverá o entendimento e reflexos de interesses difusos nas nuances que perpassam as alterações da legislação brasileira, sobretudo as tributárias.

\section{REFERÊNCIAS}

Affonso, R. B. (1995). A federação no Brasil: impasses e perspectivas. São Paulo: Desenvolvimento AdministrativoFUNDAP.

Arrow, J. K. (1951). Social choice and individual values. Cowles Foundation.

Bucchanan, J. M., Tullock, G. (1962). The calculus of consent (Vol. 3). Ann Arbor: University of Michigan Press.

Constituição Federal de 1988. (1988). Diário Oficial da União, Brasília, DF, 05 out.

Castro, G. (2010). Ideologia do brasileiro: "Farinha pouca, meu pirão primeiro". O Tempo. Recuperado, em 01 de novembro de 2018, de https://www.otempo.com.br/opini\%C3\%A3o/gilda-de-castro/ideologia-do-brasileirofarinha-pouca-meu-pir\%C3\%A3o-primeiro-1.693.

Confaz (2004). Conselho Nacional de Política Fazendária. Convênio ICMS 73/04. Autoriza os Estados que menciona a conceder isenção de ICMS nas operações ou prestações internas destinadas a órgãos do Poder Executivo da Administração Pública Estadual Direta e suas Fundações e Autarquias. Diário Oficial da União de 30.set.

Confaz (2018). Conselho Nacional de Política Fazendária. Arrecadação de Tributos. Acesso em junho 2018.

Crespi, G., Giuliondori, D., Giuliodori, R., \& Rodiguez, A. (2016). The effectiveness of tax incentives for R\&D+ $\mathrm{i}$ in developing countries: The case of Argentina. Research Policy, 45(10), 2023-2035.

Cruz, A. A. (2011). Teoria da escolha pública: Uma visão geral de seus elementos sobre a ótica de Gordon Tullock em sua obra Government Failure. Revista Virtual Faculdades Milton Campos, 9(1), 1-19.

Downs, A. (1957). An economic theory of political action in a democracy.Journal of political economy, 65(2), 135-150.

Eisenhardt, K. M. (2015). Teoria da agência: uma avaliação e revisão. Revista de Governança Corporativa, 2(1), 1-36.

Godoi, C. G., Mello, E. R. (2016). Os sistemas tributários norte-americano e brasileiro sob a ótica da justiça tributária e da tributação justa. Revista de Direito Internacional, Econômico e Tributário - RDIET, 11(2), 172-195.

Jensen, M., \& Meckling, W. (1976). Theory of the firm: Managerial behavior, agency costs, and ownership structure. Journal of Financial Economics, 3(1), 305-360.

Kleven, H. J., Kreiner, C. T., Saez, E. (2016). Why can modern governments tax so much? An agency model of firms as fiscal intermediaries. Economica, 83(330), 219-246.

Laporta, T. (2016). 20 estados e DF sobem ICMS no país; veja quais impostos aumentaram. G1. Recuperado, em 07 de setembro de 2016, de http://g1.globo.com/economia/noticia/2016/01/20-estados-e-df-sobem-icms-no-pai s-veja-quais-impostos-aumentaram.html

Lei Complementar N. 87, de 13 de setembro de 1996. (1996). Dispõe sobre o imposto dos Estados e do Distrito Federal sobre operações relativas à circulação de mercadorias e sobre prestações de serviços de transporte interestadual e intermunicipal e de comunicação, e dá outras providências. (LEI KANDIR). Diário Oficial da União de 16 set.

Lei Complementar N. 101 de 04 de maio de 2000. (2000). Estabelece normas de finanças públicas voltadas para a responsabilidade na gestão fiscal e dá outras providências. Diário Oficial da União. de 5. mai.

Lei N. 4.320 de 17 de março de 1964. (1964). Estatui Normas Gerais de Direito Financeiro para elaboração e controle dos orçamentos e balanços da União, dos Estados, dos Municípios e do Distrito Federal. Diário Oficial do Município de 04. Maio.

Lei N. 5.172 de 25 de outubro de 1966. (1966). Dispõe sobre o Sistema Tributário Nacional e institui normas gerais de direito tributário aplicáveis à União, Estados e Municípios. Diário Oficial da União de 31.out.

Mendes, M. (2004). Federalismo fiscal. Economia do Setor Público no Brasil. Elsevier, 421-461

Mutlu, C., Peng, M., \& Van Essen, M. (2015). Privatization and principal-principal conflicts in transition economies. Shareholder Empowerment., 239-265.

Novelino, M. (2015). Curso de direito constitucional. Salvador: JusPODIVM. 
Sagres (2018). Sistema de Acompanhamento de Gestão de Recursos da Sociedade. Tribunal de Contas do Estado da Paraíba (TCE/PB). Despesa.

STN (2015). Secretaria do Tesouro Nacional. Responsabilidade Fiscal.

STN (2018). Secretaria do Tesouro Nacional. Finanças do Brasil (FINBRA).

Schumpter, J. (1942). Capitalism, Socialism and Democracy. New York: HarperPER.

Tullock, G., Brady, G. L., Seldon, A. (2002). Government failure: a primer in public choice. Cato Institue.

\section{BY-NC-ND}

